\title{
FAVORABLE PROGNOSTIC VALUE OF TISSUE HUMAN KALLIKREIN 11 (hK11) IN PATIENTS WITH OVARIAN CARCINOMA
}

Carla A. Borgoño ${ }^{1,2}$, Stefano Fracchioli ${ }^{3}$, George M. Yousef ${ }^{1,2}$, Irene A. Rigault de la Longrais ${ }^{3}$, Liu-Ying Luo ${ }^{1,2}$, Antoninus Soosaiplllai ${ }^{1}$, Manuela PuOPOlo ${ }^{3}$, Linda Grass ${ }^{1}$, Andreas Scorilas ${ }^{4}$, Eleftherios P. Diamandis ${ }^{1,2} *$ and Dionyssios KaTSAROs ${ }^{3}$

${ }^{1}$ Department of Pathology and Laboratory Medicine, Mount Sinai Hospital, Toronto, Ontario, Canada

${ }^{2}$ Department of Laboratory Medicine and Pathobiology, University of Toronto, Toronto, Ontario, Canada

${ }^{3}$ Department of Gynecology, Gynecologic Oncology Unit, University of Turin, Turin, Italy

${ }^{4}$ National Center of Scientific Research "Demokritos", IPC, Athens, Greece

Human kallikrein II (hK I I/trypsin-like serine protease/ TLSP, encoded by the KLKII gene) is a member of the kallikrein family of secreted serine proteases. Recently, we developed a highly sensitive and specific immunoassay for hKII and found that this protease is expressed in the prostate, stomach and trachea as well as in amniotic fluid and milk of lactating women. Elevated serum hKII levels were found in $60 \%$ of men with prostate cancer and $70 \%$ of women with ovarian cancer. Also, hKII expression was found to be under the regulation of steroid hormones, particularly estrogens, at the level of $K L K I I$ transcription. We hypothesized that hKI I may be implicated in endocrine-related malignancies and serve as a novel prostate and ovarian cancer serological marker. The aim of our study was to examine if hK I I expression in ovarian tumors bears any prognostic significance. The concentration of hKII (ng per $\mathrm{mg}$ of total protein) in 104 ovarian tumor cytosolic extracts was quantified and correlated with clinicopathologic variables and outcome over a median follow-up period of 67 months. Outcome was defined as progression-free survival (PFS) and overall survival (OS). hKII concentration in ovarian tumor cytosols ranged from $0-21 \mathrm{ng} / \mathrm{mg}$ of total protein, with a median of 0.54 $\mathrm{ng} / \mathrm{mg}$. An optimal cutoff value of $0.54 \mathrm{ng} / \mathrm{mg}$ was selected to categorize tumors as hKI I-positive or -negative. hK I I-positive tumors were more frequently associated with early stage (Stage I/II) disease, pre-/peri-menopausal status and patients who exhibited complete or partial response to chemotherapy $(p<0.05)$. Univariate analysis revealed that patients with hKI I-positive tumors had a significantly decreased risk of relapse with a hazard ratio $(H R)$ of $0.45(p=0.007)$ and death (HR of 0.34, $p=0.005)$. Cox multivariate analysis indicated that hKII was an independent prognostic indicator of OS (HR of 0.4I, $p=0.025$ ). Kaplan-Meier survival curves further confirmed that women with hKII-positive tumors have longer PFS and OS $(p=0.005$ and $p=0.003$, respectively). Similarly, in the subgroup of patients with grade I-2 tumors, hKII-positivity was associated with higher OS in both univariate and multivariate analysis (HR of 0.23 and $0.17, p<$ 0.05). Finally, in women with optimal debulking after surgery ( $<I \mathrm{~cm}$ residual tumor), hKI I positivity was associated with a slower disease progression. These results indicate that hKII is a novel, independent marker of favorable prognosis in patients with ovarian cancer.

(c) 2003 Wiley-Liss, Inc.

Key words: serine proteases; kallikreins; cancer biomarkers; prognostic markers; ovarian cancer; human kallikrein 11; hK11

Ovarian cancer is the sixth most common malignancy among women worldwide, accounting for $4.4 \%$ of female cancers and the most lethal of all gynecological cancers. ${ }^{1,2}$ Since ovarian carcinomas initially generate common and transient nonspecific symptoms, their prompt diagnosis is difficult. Over two-thirds of ovarian tumors are discovered at advanced International Federation of Gynecologists and Obstetricians (FIGO) Stages III/IV, when 5 -year survival rates after treatment are only $18 \%{ }^{3}$ When diagnosed at FIGO Stages I/II, this figure increases to $87 \%$.

In addition to pelvic examination and transvaginal ultrasound, tumor markers contribute to the screening, diagnosis and monitoring of this malignancy, and represent important prognostic vari- ables that aid in predicting response to therapy and disease recurrence. ${ }^{4}$ The most extensively studied serological ovarian cancer marker is CA125. 5 Due to its limitations as a diagnostic, prognostic and screening tool, other biomarkers have been identified..$^{5,6}$ Among these are CA19-9, CA15-3, TAG-72, OVX1, HER2, inhibin, the free $\beta$ subunit of human chorionic gonadotropin (HCG $\beta$ ) and CYFRA $21^{-17-11}$ as well as serine proteases including pros$\operatorname{tasin}^{12}$ and several members of the human tissue kallikrein family.

Human tissue kallikreins (hKs) are serine proteases encoded by 15 structurally similar genes that colocalize to chromosome 19q13.4. ${ }^{13}$ Accumulating evidence indicates that many kallikreins are differentially expressed in hormone-dependent cancers including prostate, ${ }^{14-16}$ testicular, ${ }^{17}$ breast $^{18,19}$ and ovarian ${ }^{20-25}$ tumors and several possess prognostic value. ${ }^{13}$ In addition to prostate specific antigen (PSA)/hK3, the best tumor marker available in clinical medicine, ${ }^{26}$ other kallikreins such as hK6, 10 and 11 have emerged as potential serological epithelial ovarian cancer markers. ${ }^{27-30}$

Human kallikrein gene 11 (KLK11) was cloned using polymerase chain reaction (PCR) based assays from human hippocampus cDNA $^{31}$ and was subsequently recognized as a novel member of the kallikrein gene family. ${ }^{32}$ Its protein product, hK11, which was previously referred to as trypsin-like serine protease (TLSP) and protease serine 20 (PRSS20), encodes for a serine protease of 260 amino acids in length. Of these 260, 18 amino acids constitute the signal peptide and 3 amino acids, the activation peptide. hK11 shares $41-51 \%$ identity with other kallikreins including PSA. ${ }^{32}$

Recently, a highly sensitive and specific immunofluorometric assay for hK11 was developed and used to determine the distribution of this kallikrein in human tissues and biologic fluids and study its clinical utility. ${ }^{29} \mathrm{hK} 11$ was found to be expressed in the ovary, prostate, stomach, trachea, skin and colon and in seminal plasma, amniotic fluid and milk of lactating women. Preliminary evidence indicates that serum hK11 levels are elevated in 70\% (14 out of 20 samples) of women with ovarian carcinoma, implying that this kallikrein may be a novel serological marker for ovarian cancer. Immunohistochemic analysis demonstrated that hK11 is present in the cytoplasm of epithelial cells derived from invasive

Grant sponsor: National Cancer Institute of the United States; Grant number: 1R1CA93568-O1A1; Grant sponsor: Italian Association for Cancer Research (AIRC).

*Correspondence to: Department of Pathology and Laboratory Medicine, Mount Sinai Hospital, 600 University Avenue, Toronto, Ontario, Canada M5G 1X5. Fax: +416-586-8628.

E-mail: ediamandis@mtsinai.on.ca

Received 30 September 2002; Revised 2 January 2003; Accepted 28 January 2003

DOI 10.1002/ijc.11296 
TABLE I - DISTRIBUTION OF NUMERICAL VARIABLES OF OVARIAN CANCER PATIENTS

\begin{tabular}{|c|c|c|c|c|c|c|c|}
\hline \multirow{2}{*}{ Variable } & \multirow{2}{*}{ Mean $\pm \mathrm{SE}^{1}$} & \multirow{2}{*}{ Range } & \multicolumn{5}{|c|}{ Percentiles (median) } \\
\hline & & & 10 & 25 & 50 & 75 & 90 \\
\hline hK11 (ng/mg) & $1.55 \pm 0.25$ & $0.00-21$ & 0.00 & 0.007 & 0.54 & 2.11 & 4.71 \\
\hline Residual tumor $(\mathrm{cm})$ & $2.66 \pm 0.31$ & $0.0-9.0$ & 0.0 & 0.0 & 1.5 & 5.0 & 8.0 \\
\hline Age (years) & $59.0 \pm 1.13$ & $25.0-81.0$ & 42.8 & 51.0 & 59.0 & 69.0 & 73.2 \\
\hline
\end{tabular}

${ }^{1}$ Standard error.

papillary serous carcinoma of the ovary. ${ }^{29}$ Also, similar to other kallikreins, the KLK11 gene was found to be upregulated by estradiol in 2 breast cancer cell lines, ${ }^{29}$ further suggesting a role for this protease in endocrine-related malignancies. The aim of our study, given the above, was to determine if hK11 expression in ovarian tumors bears any prognostic significance.

\section{MATERIAL AND METHODS}

\section{Ovarian cancer patients and specimens}

A total of 104 patients with primary ovarian cancer were examined in our study, ranging in age from $25-81$ years, with a median age of 59 (Table 1). These patients underwent surgery and treatment for ovarian cancer at the Department of Gynecology of the University of Turin, Turin, Italy between July of 1991 and April of 1999. Histologic examination, performed during intrasurgery frozen section analysis, allowed representative portions of each tumor containing more than $80 \%$ tumor cells to be selected for storage until analysis. Patients were monitored for survival and disease progression (no apparent progression or progression) for a median duration of 67 months. Follow-up information was available for 92 patients, among which $52(56 \%)$ had relapsed and $32(33 \%)$ had died.

Clinical and pathologic information documented at the time of surgery included tumor stage, grade, histotype, residual tumor size, debulking success, menopausal status and response to chemotherapy (Table 2). The staging of tumors was in accordance with the FIGO criteria, ${ }^{33}$ grading was established according to Day et al..$^{34}$ and the classification of histotypes was based on the WHO and FIGO recommendations. ${ }^{35}$

Patients with disease at all clinical stages (I-IV) and grades (1-3) were represented in our study. Of the 104 ovarian tumors, the majority $(53 ; 52 \%)$ were of the serous papillary histotype, followed by endometriod $(18 ; 17 \%)$, undifferentiated $(14 ; 13 \%)$, clear cell $(7 ; 7 \%)$, mucinous $(4 ; 4 \%)$ or were unclassified $(8 ; 7 \%)$. The residual size of tumors ranged from $0-9 \mathrm{~cm}$, with a median of $1.5 \mathrm{~cm}$.

Investigations were carried out in accordance with the ethical standards of the Helsinki Declaration of 1975, as revised in 1983, and were approved by the Institute of Obstetrics and Gynecology, Turin, Italy.

\section{Preparation of cytosolic extracts}

Tumor specimens were snap-frozen in liquid nitrogen immediately after surgery and stored at $-80^{\circ} \mathrm{C}$ until extraction. Frozen tissues $(20-100 \mathrm{mg})$ were pulverized on dry ice to a fine powder and added to 10 volumes of extraction buffer (50 mM Tris, $\mathrm{pH} 8.0$, $150 \mathrm{mM} \mathrm{NaCl}, 5 \mathrm{mM}$ EDTA, $10 \mathrm{~g} / \mathrm{L}$ of NP-40 surfactant, $1 \mathrm{mM}$ phenylmethyl sulphonyl fluoride, $1 \mathrm{~g} / \mathrm{L}$ of aprotinin, $1 \mathrm{~g} / \mathrm{L}$ of leupeptin). The resulting suspensions were incubated on ice for 30 min, with repeated shaking and vortexing every $10 \mathrm{~min}$. The mixtures were then centrifuged at $10,000 \mathrm{~g}$ at $4^{\circ} \mathrm{C}$ for $30 \mathrm{~min}$ and the supernatant (cytosolic extract) was collected and stored at $-80^{\circ} \mathrm{C}$ until further analysis. Protein concentration of the extracts was determined using the bicinchoninic acid method, with albumin as standard (Pierce Chemical Co., Rockford, IL).

\section{Measurement of hK11 in ovarian cytosolic extracts}

The concentration of hK11 in the cytosolic extracts was quantified using a highly sensitive and specific noncompetitive immu-
TABLE II - ASSOCIATIONS BETWEEN hK11 STATUS AND OTHER VARIABLES IN 104 PATIENTS WITH EPITHELIAL OVARIAN CANCER ${ }^{1}$

\begin{tabular}{|c|c|c|c|c|}
\hline \multirow{2}{*}{ Variable } & \multirow{2}{*}{ Patients } & \multicolumn{2}{|c|}{ No. of patients (\%) } & \multirow{2}{*}{$p$-value } \\
\hline & & hK11 negative & hK11 positive & \\
\hline \multicolumn{5}{|l|}{ Stage } \\
\hline I/II & 33 & $11(33.3)$ & $22(66.7)$ & $0.035^{2}$ \\
\hline III/IV & 69 & $39(56.5)$ & $30(43.5)$ & \\
\hline $\mathrm{X}^{3}$ & 2 & & & \\
\hline \multicolumn{5}{|l|}{ Grade } \\
\hline $\mathrm{G} 1 / \mathrm{G} 2$ & 30 & $15(50.0)$ & $15(50.0)$ & $0.84^{2}$ \\
\hline G3 & 71 & $34(47.9)$ & $37(52.1)$ & \\
\hline $\mathrm{X}$ & 3 & & & \\
\hline \multicolumn{5}{|l|}{ Histotype } \\
\hline Serous & 53 & $26(49.1)$ & $27(50.9)$ & \\
\hline Endometrioid & 18 & 7 (38.9) & $11(61.1)$ & \\
\hline Mucinous & 4 & $2(50.0)$ & $2(50.0)$ & $0.32^{4}$ \\
\hline Clear cell & 7 & $6(85.7)$ & $1(14.3)$ & \\
\hline Undifferentiated & 14 & $6(42.9)$ & $8(57.1)$ & \\
\hline $\mathrm{X}$ & 8 & & & \\
\hline \multicolumn{5}{|l|}{ Debulking success 5} \\
\hline OD & 46 & $28(53.8)$ & $24(46.2)$ & $0.16^{2}$ \\
\hline SO & 52 & $18(39.1)$ & $28(60.9)$ & \\
\hline $\mathrm{X}$ & 6 & & & \\
\hline \multicolumn{5}{|l|}{ Menopause } \\
\hline Pre/peri & 26 & 7 (26.9) & $19(73.1)$ & $0.007^{2}$ \\
\hline Post & 81 & $47(58.0)$ & $34(42.0)$ & \\
\hline $\mathrm{X}$ & 2 & & & \\
\hline \multicolumn{5}{|l|}{ Response to $\mathrm{CTX}^{6}$} \\
\hline NC/PD & 13 & $10(76.9)$ & $3(23.1)$ & $0.033^{2}$ \\
\hline CR/PR & 78 & $33(42.3)$ & $45(57.7)$ & \\
\hline $\mathrm{NE}$ & 13 & & & \\
\hline
\end{tabular}

${ }^{1}$ Cutoff point: $0.55 \mathrm{ng} / \mathrm{mg}$ protein equals to 50 th percentile. $-{ }^{2}$ Fisher's exact test. $-{ }^{3} \mathrm{X}$, status unknown. $-{ }^{4} \chi^{2}$ test. $-{ }^{5} \mathrm{OD}$, optimal debulking $(0-1 \mathrm{~cm})$; SO, suboptimal debulking $(>1 \mathrm{~cm}) .-{ }^{6} \mathrm{CTX}$, chemotherapy; $\mathrm{NC}$, no change; $\mathrm{PD}$, progressive disease; CR, complete response; PR, partial response; NE, not evaluated.

noassay for hK11 that was previously described and evaluated. ${ }^{29}$ Briefly, a mouse anti-hK11 monoclonal antibody was captured with sheep antimouse IgG, Fc fragment-specific antibodies (Jackson Immunoresearch, West Grove, PA), on 96-well polystyrene micortiter plates. hK11 calibrators (recombinant hK11 in $60 \mathrm{~g} / \mathrm{L}$ BSA) or cytosolic extracts $(100 \mu \mathrm{L})$ were then applied to each well in duplicate, incubated for $2 \mathrm{hr}$ with gentle shaking and then washed. Rabbit anti-hK11 polyclonal antiserum was subsequently applied, incubated and washed. Finally, alkaline phosphatase-conjugated goat anti-rabbit IgG (Jackson Immunoresearch) was added, incubated and washed as before. Signal detection and data reduction were performed automatically by the CyberFluor 615 Immunoanalyzer (Nordion International, Kanata, Canada) which uses time resolved fluorometry, as described elsewhere. ${ }^{36}$ The detection range of this assay is $0.1-50 \mu \mathrm{g} / \mathrm{L}$. hK11 concentrations in $\mu \mathrm{g} / \mathrm{L}$ were converted to ng of $\mathrm{hK} 11 / \mathrm{mg}$ of total protein to adjust for the amount of tumor tissue extracted.

\section{Statistical analysis}

Statistical analysis was performed with SPSS software (SPSS Inc., Richmond, CA). Patients were divided into different groups in order to analyze date according to clinical and pathologic parameters. Since the distribution of hK11 mass per mg total protein in the ovarian tumor extracts was not Gaussian, the non- 
parametric Mann-Whitney U test was used to determine differences between 2 groups. This test treated hK11 concentration in the tumor extract (ng/mg total protein) as a continuous variable.

hK11 values were also classified into 2 categories, namely hK11-positive and hK11-negative. The relationships between hK11 status (positive or negative) of the ovarian tumor extracts to various clinicopathologic variables were analyzed with the $\chi^{2}$ test and the Fisher's exact test, as appropriate.

For survival analysis, 2 different end points, cancer relapse (either local recurrence or distant metastasis) and death, were used to calculate progression free (PFS) and overall survival (OS), respectively. PFS was defined as the time interval between the date of surgery and the date of identification of the recurrence of the metastatic disease. OS was defined as the time interval between the date of surgery and the date of death. The impact of hK11 on patient survival (PFS and OS) was assessed with the hazard ratio (HR), which was the relative risk of relapse or death in the hK11-positive group, calculated with the Cox univariate and multivariate proportional hazard regression model. ${ }^{37}$ In the multivariate analysis, the clinical and pathologic variables that may affect survival, including age, stage of disease, tumor grade, histotype, and residual tumor size were adjusted.

Kaplan-Meier PFS and OS curves ${ }^{38}$ were constructed to demonstrate survival differences between the hK11-positive and hK11negative patients. The differences between the survival curves

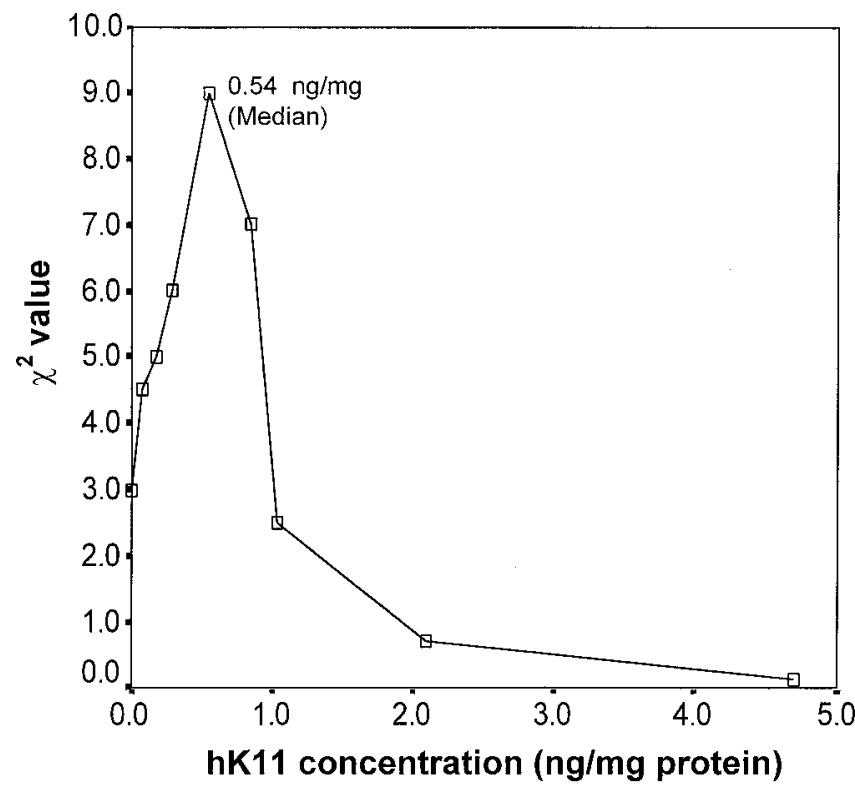

Figure 1 - Determination of the optimal cutoff value for hK11 expression. For details, see text. were tested for statistical significance using the log rank test. ${ }^{39}$ Furthermore, the patients were divided into different subgroups based on disease stage, tumor grade and debulking success, and survival analysis was then repeated for each subgroup of patients.

\section{RESULTS}

Distribution of hK11 concentration in ovarian tumor extracts

hK11 concentration in ovarian tumor cytosols from 104 patients ranged from $0-21 \mathrm{ng} / \mathrm{mg}$ of total protein, with a mean of 1.55 $\mathrm{ng} / \mathrm{mg}$ total protein and a median of $0.54 \mathrm{ng} / \mathrm{mg}$ total protein (Table 1). An optimal cutoff value of $0.54 \mathrm{ng} / \mathrm{mg}$ total protein was identified by $\chi^{2}$ analysis to distinguish hK11-positive from hK11negative tumors (Fig. 1) and categorized $50 \%$ of tumors (50th percentile) as being hK11-positive.

Relationship between hK11 status and other clinicopathological variables

The distributions of various clinicopathologic variables between hK11-postitive and hK11-negative patients are summarized in

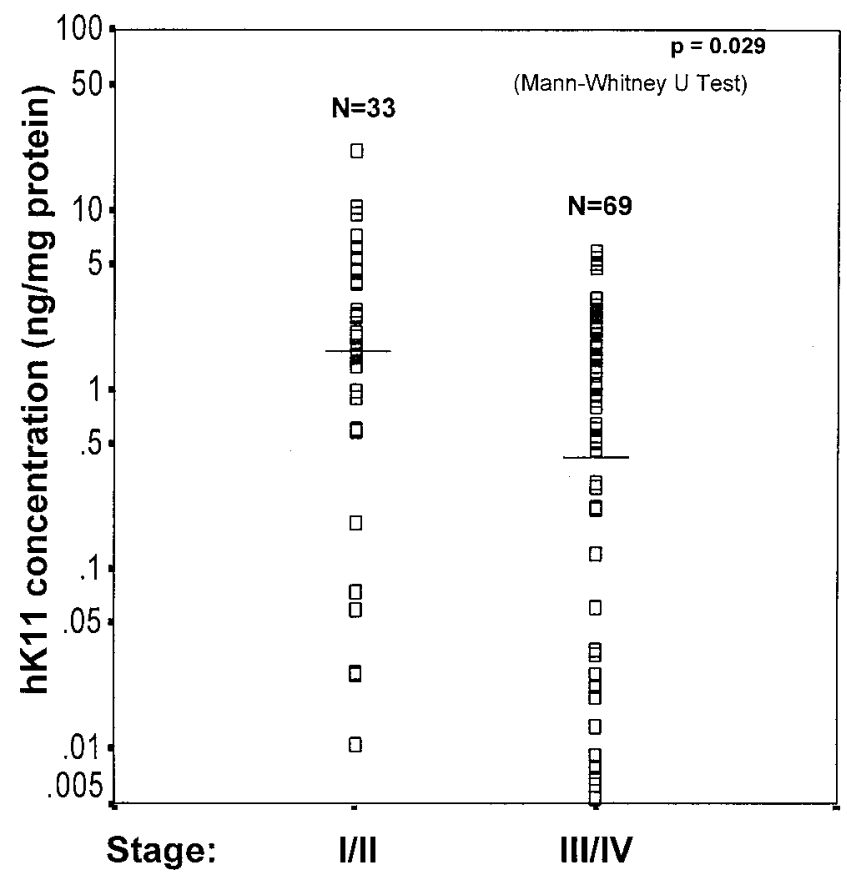

Figure 2 - Distribution of hK11 concentration in extracts from Stage I/II and Stage III/IV ovarian cancer patients. Horizontal bars indicate the mean value of hK11 concentration. The Mann-Whitney U Test indicates that hK11 concentration was significantly elevated in patients with Stage I/II ovarian cancer $(p=0.029) . n=$ number of patients

TABLE III - UNIVARIATE AND MULTIVARIATE ANALYSIS OF hK11 STATUS IN RELATION TO PROGRESSION-FREE AND OVERALL SURVIVAL

\begin{tabular}{|c|c|c|c|c|c|c|}
\hline \multirow{2}{*}{ hK11 status } & \multicolumn{3}{|c|}{ Progression-free survival } & \multicolumn{3}{|c|}{ Overall survival } \\
\hline & $\mathrm{HR}^{1}$ & $95 \% \mathrm{CI}^{2}$ & $p$-value & $\mathrm{HR}^{1}$ & $95 \% \mathrm{CI}^{2}$ & $p$-value \\
\hline \multicolumn{7}{|c|}{ Univariate analysis $(n=92)$} \\
\hline \multicolumn{7}{|c|}{ Categorical variable $\mathrm{e}^{3}$} \\
\hline Negative & 1.00 & & & 1.00 & & \\
\hline Positive & 0.45 & $0.25-0.80$ & 0.007 & 0.34 & $0.16-0.72$ & 0.005 \\
\hline Continuous variable & 0.92 & $0.81-1.05$ & 0.22 & 0.86 & $0.72-1.04$ & 0.12 \\
\hline \multicolumn{7}{|c|}{ Multivariate analysis $(n=86)$} \\
\hline \multicolumn{7}{|c|}{ Categorical variable ${ }^{3}$} \\
\hline Negative & 1.00 & & & 1.00 & & \\
\hline Positive & 0.61 & $0.34-1.10$ & 0.099 & 0.41 & $0.19-0.89$ & 0.025 \\
\hline
\end{tabular}

${ }^{1}$ Hazard ratio (HR) estimated from Cox proportional hazard regression model. $-{ }^{2}$ Confidence interval of the estimated HR.- ${ }^{3} \mathrm{hK} 11$ status based on a cutoff point equal to the 50 th percentile $(0.55 \mathrm{ng} / \mathrm{mg}$ protein $)$ of the distribution of $\mathrm{hK} 11$ values. $-{ }^{4}$ Multivariate models were adjusted for stage of disease, tumor grade, residual tumor, histologic type and age. 
Table 2. The relationships between hK11 and these variables were examined with either the $\chi^{2}$ or Fisher's exact test. No relationship was observed between hK11 status and tumor grade, histotype or debulking success. However, hK11-positive patients more frequently had early stage (Stage I/II) disease, pre-/peri-menopausal status and exhibited complete or partial response to chemotherapy $(p<0.05)$.

hK11 concentration was significantly elevated in Stage I/II ovarian cancer cytosols compared to Stage III/IV ( $p=0.029$, by the Mann Whitney U Test), indicating that a high hK11 concentration is associated with early stage disease (Fig. 2).

\section{Univariate and multivariate survival analysis}

The strength of association between hK11 positivity and survival outcome is presented in Table 3 . In univariate analysis, hK11-positive patients had a significantly decreased risk of relapse (HR of $0.45, p=0.007$ ) and death (HR of $0.34, p=0.005)$. The favorable effects of hK11 positivity on PFS and OS were lost, however, When hK11 was treated as a continuous variable. Only an association with OS remained (HR of $0.41, p=0.025$ ) when survival outcomes were adjusted for all other variables in the multivariate analysis (i.e., Cox proportional hazard regression model). As expected, Kaplan-Meier survival curves (Fig. 3) also demonstrated that patients with hK11-positive tumors have longer PFS and OS ( $p=0.005$ and $p=0.003$, respectively) compared to those who are hK11-negative.

Univariate and multivariate survival analysis in subgroups of patients

We further examined the associations between hK11 status and survival outcomes in subgroups of patients stratified by disease stage, tumor grade and debulking success (Table 4). Univariate analysis revealed that hK11 expression in patients with tumors of grades 1-2 possessed a higher OS than those with hK11-negative tumors (HR of $0.38, p=0.04$ ). The differences in OS remained significant after the data were subjected to multivariate analysis when all other known prognostic variables are included. Further, in patients with optimal debulking success after surgery $(<1 \mathrm{~cm}$ residual tumor), hK11 positivity correlated with a longer PFS in univariate and multivariate analysis (HR of $0.13, p=0.013$, HR of $0.16, p=0.038$, respectively).

Although marginally significant, patients with Stage I/II disease with hK11-positive ovarian tumors were less likely to relapse (HR of $0.11, p=0.052$ ).

\section{DISCUSSION}

Ovarian cancer is the fourth most common (4\%), fifth most lethal cancer $(5 \%)$, and the most frequent cause of death from gynecologic cancer (53\%) among U.S. women. ${ }^{1}$ With a lack of early warning symptoms or reliable screening methods, the immediacy of discovering novel tumor markers to facilitate in the diagnosis and to provide insight regarding prognosis of established ovarian carcinoma becomes apparent. Measurements of single tumor markers have shown to be of insufficient sensitivity or specificity. Only in combination with CA-125 can they increase the sensitivity and specificity of detecting and monitoring ovarian carcinomas. ${ }^{40,41}$ The use of multiple tumor markers in parallel could potentially detect all neoplasms of varying histotypes and identify biologic profiles to predict disease outcome and employ effective, individualized therapeutic strategies.

Our study proposes that hK11 has prognostic significance in ovarian cancer. This serine protease is more frequently expressed in early stage (I-II) and grade (1-2) ovarian carcinomas and in women of pre-/peri-menopausal status who respond better to chemotherapy. The overexpression of hK11 in ovarian tumor cytosols is significantly associated with an increased PFS and OS in both univariate and multivariate analyses. $\mathrm{hK} 11$ positivity retained its independent prognostic value in the subgroup of patients with grades 1-2 tumors. Also, in patients with optimal debulking suc-
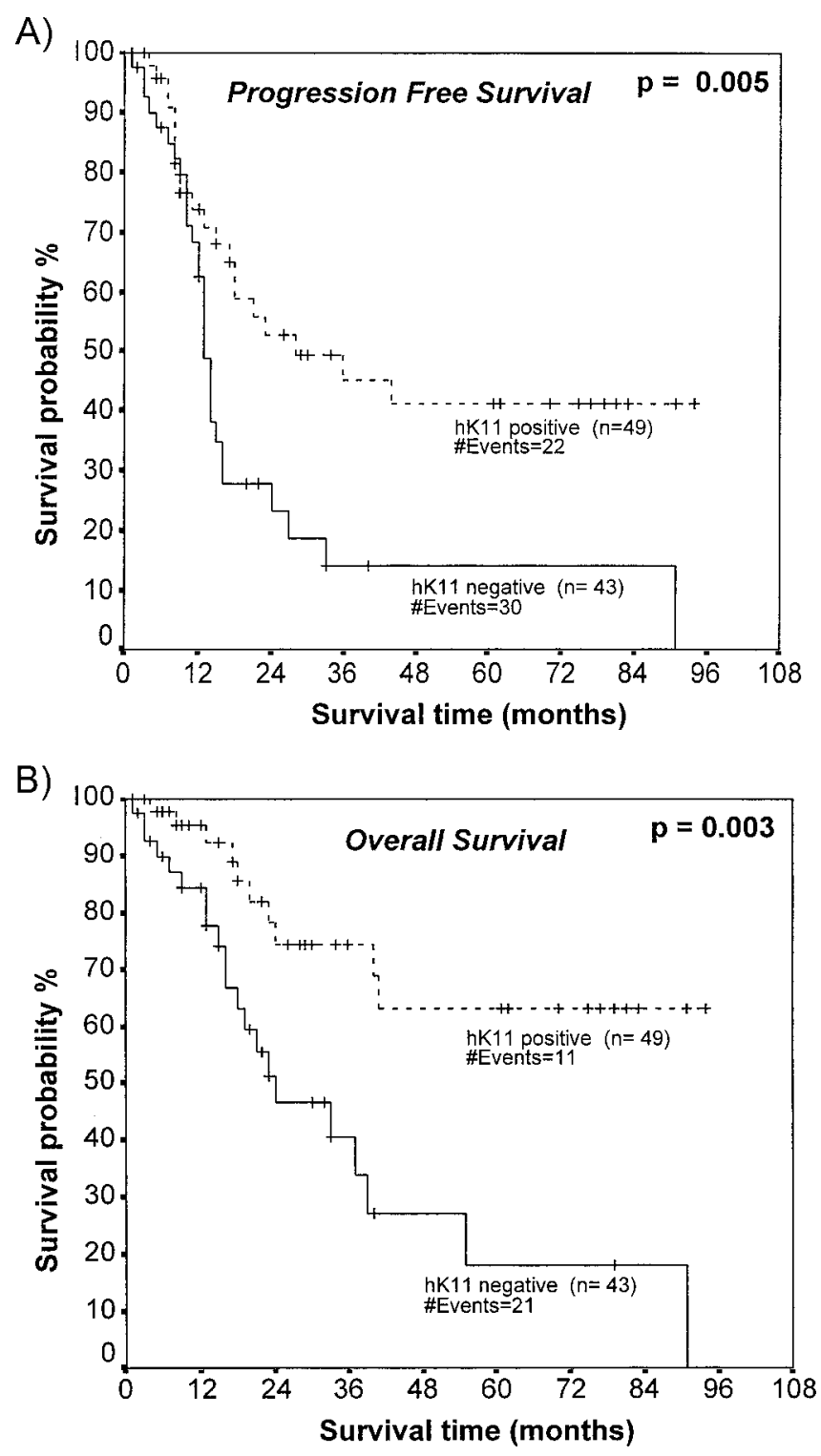

Figure 3 - Kaplan-Meier survival curves for progression-free survival $(a)$ and overall survival $(b)$ in patients with hK11-positive and negative ovarian tumors. $n=$ number of samples.

cess $(<1 \mathrm{~cm}$ residual tumor) after surgery, high hK11 levels predict favorable disease progression. Hence, hK11 is an independent indicator of favorable prognosis in ovarian cancer patients.

Previous studies have similarly shown that many other kallikrein genes $(K L K 4,5,6,7,8,9,14$, and 15$)$ are also differentially expressed in ovarian cancer and several possess clinical utility. ${ }^{20-24,42,43}$ Of relevance is the overexpression of $K L K 8,9$ and 14 in early stage ovarian tumors, which is associated with a favorable prognosis, analogous to hK11 in our study. Conversely, the remainder of the genes exhibit higher expression levels in advanced and more aggressive cancer and are associated with poor prognosis. Comparable investigations to determine the prognostic value of hK6 and hK10 in ovarian cancer cytosols also oppose the results obtained for hK11. That is, high levels of these kallikreins were associated with late stage disease and decreased disease-free and overall survival (Diamandis et al. ${ }^{29}$ and our unpublished data). It is plausible to hypothesize, therefore, that human kallikreins function together in the normal physiology of the ovary and in promoting or inhibiting ovarian carcinogenesis at different stages. 
TABLE IV - ASSOCIATIONS BETWEEN hK11 AND PFS AND OS. IN SUBGROUPS OF PATIENTS STRATIFIED BY TUMOR GRADE, STAGE AND DEBULKING SUCCESS

\begin{tabular}{|c|c|c|c|c|c|c|}
\hline \multirow{2}{*}{ Variable } & \multicolumn{3}{|c|}{ Progression-free survival } & \multicolumn{3}{|c|}{ Overall survival } \\
\hline & $\mathrm{HR}^{1}$ & $95 \% \mathrm{CI}^{2}$ & $p$-value & $\mathrm{HR}^{1}$ & $95 \% \mathrm{CI}^{2}$ & $p$-value \\
\hline \multicolumn{7}{|c|}{ Tumor grade $1-2(n=30)$} \\
\hline hK11 unadjusted & 0.38 & $0.12-1.16$ & 0.091 & 0.23 & $0.06-0.93$ & 0.040 \\
\hline hK11 adjusted ${ }^{3}$ & 0.31 & $0.06-1.48$ & 0.14 & 0.17 & $0.031-0.95$ & 0.044 \\
\hline \multicolumn{7}{|c|}{ Tumor grade $3(n=59)$} \\
\hline hK11 unadjusted & 0.43 & $0.22-0.84$ & 0.015 & 0.45 & $0.19-1.08$ & 0.075 \\
\hline hK11 adjusted $^{3}$ & 0.55 & $0.26-1.18$ & 0.13 & 0.68 & $0.26-1.74$ & 0.42 \\
\hline \multicolumn{7}{|l|}{ Stage I-II $(n=25)$} \\
\hline hK11 unadjusted & 0.11 & $0.01-1.02$ & 0.052 & 0.22 & $0.02-2.44$ & 0.21 \\
\hline hK11 adjusted ${ }^{4}$ & 0.26 & $0.02-3.03$ & 0.28 & 0.59 & $0.03-10.2$ & 0.71 \\
\hline \multicolumn{7}{|l|}{ Stage III $(n=61)$} \\
\hline hK11 unadjusted & 0.81 & $0.44-1.43$ & 0.46 & 0.65 & $0.30-1.42$ & 0.28 \\
\hline hK11 adjusted ${ }^{4}$ & 0.82 & $0.45-1.51$ & 0.54 & 0.53 & $0.23-1.20$ & 0.13 \\
\hline \multicolumn{7}{|c|}{ Optimal debulking $(n=38)$} \\
\hline hK11 unadjusted & 0.13 & $0.03-0.65$ & 0.013 & 0.12 & $0.014-1.17$ & 0.069 \\
\hline hK11 adjusted $^{5}$ & 0.16 & $0.09-0.91$ & 0.038 & 0.24 & $0.018-3.23$ & 0.28 \\
\hline \multicolumn{7}{|c|}{ Suboptimal debulking $(n=48)$} \\
\hline hK11 unadjusted & 0.88 & $0.47-1.63$ & 0.67 & 0.71 & $0.32-1.58$ & 0.41 \\
\hline hK11 adjusted $^{5}$ & 0.87 & $0.46-1.65$ & 0.68 & 0.69 & $0.31-1.58$ & 0.39 \\
\hline
\end{tabular}

${ }^{1}$ Hazard ratio (HR) estimated from Cox proportional hazard regression model.- ${ }^{2}$ Confidence interval of the estimated HR. $-{ }^{3}$ Multivariate models were adjusted for stage of disease, residual tumor, histologic type and age. ${ }^{4}$ Multivariate models were adjusted for tumor grade, residual tumor, histologic type and age. $-{ }^{5}$ Multivariate models were adjusted for stage of disease, tumor grade, histologic type and age.

Other serine proteases, including trypsin, ${ }^{44,45}$ testisin, ${ }^{46}$ hep$\sin ,{ }^{47}$ and TADG-15 (tumor-associated differentially expressed gene 15$)^{48}$ in addition to human kallikreins are overexpressed in ovarian cancer. Thus, it would be appealing to study the overall panel of kallikrein and serine protease expression overall in this malignancy to determine the combined diagnostic or prognostic potential.

The overexpression of hK11 in early stage ovarian tumors, in addition to the elevation of hK11 in the serum of ovarian cancer patients, ${ }^{29}$ indicates that $K L K 11$ gene transcription is increased during ovarian carcinogenesis, suggesting a role for this protease in cancer progression. It was recently shown that $K L K 11$ is under steroid hormone regulation, particularly estrogens. ${ }^{29}$ Epidemiologic evidence implicates a role for endocrinologic factors, including estrogens, in the etiology of epithelial ovarian cancer. ${ }^{49}$ In addition, 30-63\% of epithelial ovarian tumors express the estrogen receptor (ER), ${ }^{50}$ a requirement for hormone responsiveness, and ER- $\alpha$ is markedly increased during ovarian carcinogenesis. ${ }^{51}$ It is likely, therefore, that estrogen-ER complexes turn on KLK11 gene transcription leading to hK11 overexpression.

Estrogens appear to have a dual role in the progression of ER-positive and hormone responsive ovarian cancer cells in that they inhibit their invasion and motility and are mitogenic. ${ }^{52,53}$ The molecular mechanisms by which estrogens prevent local metastasis at early stages is unclear. These effects may be mediated by estrogen induced proteins, including compenents of the extracel- lular matrix ${ }^{54}$ serine protease inhibitors ${ }^{55,56}$ and serine proteases, including tissue-type plasminogen activator (t-PA), ${ }^{57}$ which displays prognostic value in breast cancer. Taken together, it is not unreasonable to speculate that hK11, an estrogen induced protease, may play a role in the inhibition of ovarian cancer metastasis in early stage carcinomas by initiating or terminating certain pathologic events through the cleavage of specific substrates, including proteases, growth factors or oncogenes. This would be in agreement with the observation that hK11 overexpression in early stage ovarian cancer is an indicator of a favorable prognosis. Further basic and clinical studies are required to specify the activity of hK11 in both the normal and malignant ovary.

In summary, this is the first report attributing prognostic value to hK11 in ovarian cancer. Although its clinical utility is yet to be explored, it may be used in a panel with other kallikreins, serine proteases or biomarkers to improve its individual prognostic potential. It may have diagnostic potential in addition to its prognostic worth since hK11 is elevated in the serum of women with ovarian cancer.

\section{ACKNOWLEDGEMENTS}

This work was supported by a grant to Dr. Diamandis from the National Cancer Institute of the United States (Grant \# 1R1CA93568O1A1). The research of Dr. S. Fracchioli, Dr. I. Rigault de la Longrais, Dr. M. Puopolo and Dr. D. Katsaros is partially supported by the Italian Association for Cancer Research (AIRC).

\section{REFERENCES}

1. Jemal A, Thomas A, Murray T, Thun M. Cancer statistics, 2002. CA Cancer J Clin 2002;52:23-47.

2. Parkin DM, Pisani P, Ferlay J. Estimates of the worldwide incidence of 25 major cancers in 1990. Int J Cancer 1999;80:827-841.

3. Fiorica JV, Roberts WS. Screening for ovarian cancer. Cancer Control 1996;3:120-129.

4. Meyer T, Rustin GJ. Role of tumour markers in monitoring epithelial ovarian cancer. Br J Cancer 2000;82:1535-1538.

5. Bast Jr RC, Xu FJ, Yu YH, Barnhill S, Zhang Z, Mills GB. CA 125: the past and the future. Int J Biol Markers 1998;13:179-187.

6. Rosenthal AN, Jacobs IJ. The role of CA 125 in screening for ovarian cancer. Int J Biol Markers 1998:13:216-220.

7. Berek JS, Bast Jr RC. Ovarian cancer screening. The use of serial complementary tumor markers to improve sensitivity and specificity for early detection. Cancer 1995;76:2092-2096.

8. Vartiainen J, Lehtovirta P, Finne P, Stenman UH, Alfthan H. Preoperative serum concentration of hCGbeta as a prognostic factor in ovarian cancer. Int J Cancer 2001;95:313-316.
9. Gadducci A, Ferdeghini M, Cosio S, Fanucchi A, Cristofani R, Genazzani AR. The clinical relevance of serum CYFRA 21-1 assay in patients with ovarian cancer. Int J Gynecol Cancer 2001;11:277-282.

10. Burger HG, Fuller PJ, Chu S, Mamers P, Drummond A, Susil B, Neva $\mathrm{P}$, Robertson, DM. The inhibins and ovarian cancer. Mol Cell Endocrinol 2001;180:145-148.

11. Gadducci A, Ferdeghini M, Prontera C, Moretti L, Mariani G, Bianchi $\mathrm{R}$, Fioretti $\mathrm{P}$. The concomitant determination of different tumor markers in patients with epithelial ovarian cancer and benign ovarian masses: relevance for differential diagnosis. Gynecol Oncol 1992;44: 147-154.

12. Mok SC, Chao J, Skates S, Wong K, Yiu GK, Muto MG, Berkowitz RS, Cramer DW. Prostasin, a potential serum marker for ovarian cancer: identification through microarray technology. J Natl Cancer Inst 2001;93:1458-1464.

13. Yousef GM, Diamandis EP. The new human tissue kallikrein gene family: structure, function, and association to disease. Endocr Rev $2001 ; 22: 184-204$ 
14. Rittenhouse HG, Finlay JA, Mikolajczyk SD, Partin AW. Human Kallikrein 2 (hK2) and prostate-specific antigen (PSA): 2 closely related, but distinct, kallikreins in the prostate. Crit Rev Clin Lab Sci 1998;35:275-368

15. Magklara A, Scorilas A, Catalona WJ, Diamandis EP. The combination of human glandular kallikrein and free prostate-specific antigen (PSA) enhances discrimination between prostate cancer and benign prostatic hyperplasia in patients with moderately increased total PSA. Clin Chem 1999;45:1960-1966.

16. Yousef GM, Scorilas A, Jung K, Ashworth LK, Diamandis EP. Molecular cloning of the human kallikrein 15 gene (KLK15). Upregulation in prostate cancer. J Biol Chem 2001;276:53-61.

17. Luo LY, Rajpert-De Meyts ER, Jung K, Diamandis EP. Expression of the normal epithelial cell-specific 1 (NES1; KLK10) candidate tumour suppressor gene in normal and malignant testicular tissue. Br J Cancer 2001;85:220-224

18. Yousef GM, Chang A, Diamandis EP. Identification and characterization of KLK-L4, a new kallikrein-like gene that appears to be down-regulated in breast cancer tissues. J Biol Chem 2000;275: 11891-11898.

19. Yousef GM, Magklara A, Diamandis EP. KLK12 is a novel serine protease and a new member of the human kallikrein gene familydifferential expression in breast cancer. Genomics 2000;69:331-341.

20. Obiezu CV, Scorilas A, Katsaros D, Massobrio M, Yousef GM, Fracchioli S, Rigault de la Longrais IA, Arisio R, Diamandis EP. Higher human kallikrein gene 4 (KLK4) expression indicates poor prognosis of ovarian cancer patients. Clin Cancer Res 2001;7:23802386.

21. Kim H, Scorilas A, Katsaros D, Yousef GM, Massobrio M, Fracchioli S, Piccinno R, Gordini G, Diamandis EP. Human kallikrein gene 5 (KLK5) expression is an indicator of poor prognosis in ovarian cancer. Br J Cancer 2001;84:643-650.

22. Anisowicz A, Sotiropoulou G, Stenman G, Mok SC, Sager R. A novel protease homolog differentially expressed in breast and ovarian cancer. Mol Med 1996;2:624-636.

23. Magklara A, Scorilas A, Katsaros D, Massobrio M, Yousef GM, Fracchioli S, Danese S, Diamandis EP. The human KLK8 (neuropsin/ ovasin) gene: identification of two novel splice variants and its prognostic value in ovarian cancer. Clin Cancer Res 2001;7:806-811.

24. Yousef GM, Kyriakopoulou LG, Scorilas A, Fracchioli S, Ghiringhello B, Zarghooni M, Chang A, Diamandis M, Giardina G, Hartwick WJ, Richiardi G, Massobrio M, et al. Quantitative expression of the human kallikrein gene 9 (KLK9) in ovarian cancer: a new independent and favorable prognostic marker. Cancer Res 2001;61:78117818.

25. Luo LY, Katsaros D, Scorilas A, Fracchioli S, Piccinno R, Rigault de la Longrais IA, Howarth DJ, Diamandis EP. Prognostic value of human kallikrein 10 expression in epithelial ovarian carcinoma. Clin Cancer Res 2001;7:2372-2379.

26. Diamandis EP. Prostate-specific antigen-its usefulness in clinical medicine. Trends Endocrinol Metab 1998;9:310-316.

27. Diamandis EP, Yousef GM, Soosaipillai AR, Bunting P. Human kallikrein 6 (zyme/protease M/neurosin): a new serum biomarker of ovarian carcinoma. Clin Biochem 2000;33:579-583.

28. Luo LY, Bunting P, Scorilas A, Diamandis EP. Human kallikrein 10: a novel tumor marker for ovarian carcinoma? Clin Chim Acta 2001; 306:111-118.

29. Diamandis EP, Okui A, Mitsui S, Luo LY, Soosaipillai A, Grass L, Nakamura T, Howarth DJ, Yamaguchi N. Human kallikrein 11: a new biomarker of prostate and ovarian carcinoma. Cancer Res 2002;62: 295-300.

30. Diamandis EP, Yousef GM. Human tissue kallikrein gene family: a rich source of novel disease biomarkers. Expert Rev Mol Diagn 2001;1:182-90.

31. Yoshida S, Taniguchi M, Suemoto T, Oka T, He X, Shiosaka S. cDNA cloning and expression of a novel serine protease, TLSP. Biochim Biophys Acta 1998;1399:225-228.

32. Yousef GM, Scorilas A, Diamandis EP. Genomic organization, mapping, tissue expression, and hormonal regulation of trypsin-like serine protease (TLSP PRSS20), a new member of the human kallikrein gene family. Genomics 2000;63:88-96.

33. Pettersson F. Annual report on the treatment in gynecological cancer, vol. 22. Stockholm: International Federation of Gynecology and Obstetrics, 1994.

34. Day Jr TG, Gallager HS, Rutledge FN. Epithelial carcinoma of the ovary:prognostic importance of histologic grade. Natl Cancer Inst Monogr 1975;42:15-21.

35. Serov SF, Sorbin LH. Histological typing of ovarian tumors. World Health Organization, 1973.
36. Christopoulos TK, Diamandis EP. Enzymatically amplified timeresolved fluorescence immunoassay with terbium chelates. Anal Chem 1992;64:342-346.

37. Cox DR. Regression models and life tables. R Stat Soc B 1972;34: 187-202.

38. Kaplan EL, Meier P. Nonparametric estimation from incomplete observations. J Am Stat Assoc 1958;53:457-481.

39. Mantel N. Evaluation of survival data and two new rank order statistics arising in its consideration. Cancer Chemother Rep 1966;50: 163-170.

40. Woolas RP, Conaway MR, Xu F, Jacobs IJ, Yu Y, Daly L, Davies AP O'Briant K, Berchuck A, Soper JT, Clarke-Pearson DL, Rodriguez G, et al. Combinations of multiple serum markers are superior to individual assays for discriminating malignant from benign pelvic masses. Gynecol Oncol 1995;59:111-116.

41. Zhang Z, Barnhill SD, Zhang H, Xu F, Yu Y, Jacobs I, Woolas RP, Berchuck A, Madyastha KR, Bast RC Jr. Combination of multiple serum markers using an artificial neural network to improve specificity in discriminating malignant from benign pelvic masses. Gynecol Oncol 1999;73:56-61.

42. Tanimoto H, Underwood LJ, Shigemasa K, Yan Yan MS, Clarke J, Parmley TH, O'Brien TJ. The stratum corneum chymotryptic enzyme that mediates shedding and desquamation of skin cells is highly overexpressed in ovarian tumor cells. Cancer 1999;86:2074-2082.

43. Tanimoto H, Underwood LJ, Shigemasa K, Parmley TH, O'Brien TJ. Increased expression of protease $\mathrm{M}$ in ovarian tumors. Tumour Biol 2001;22:11-18.

44. Koivunen E, Itkonen O, Halila H, Stenman UH. Cyst fluid of ovarian cancer patients contains high concentrations of trypsinogen-2. Cancer Res 1990;50:2375-2378.

45. Hirahara F, Miyagi E, Nagashima Y, Miyagi Y, Yasumitsu H, Koshikawa N, Nakatani Y, Nakazawa T, Udagawa K, Kitamura H, Minaguchi H, Miyazaki K. Differential expression of trypsin in human ovarian carcinomas and low-malignant-potential tumors. Gynecol Oncol 1998;68:162-165.

46. Shigemasa K, Underwood LJ, Beard J, Tanimoto H, Ohama K, Parmley TH, O'Brien TJ. Overexpression of testisin, a serine protease expressed by testicular germ cells, in epithelial ovarian tumor cells. J Soc Gynecol Investig 2000;7:358-362.

47. Tanimoto H, Yan Y, Clarke J, Korourian S, Shigemasa K, Parmley TH, Parham GP, O'Brien TJ. Hepsin, a cell surface serine protease identified in hepatoma cells, is overexpressed in ovarian cancer. Cancer Res 1997; 57:2884-2887.

48. Tanimoto H, Underwood LJ, Wang Y, Shigemasa K, Parmley TH, O'Brien TJ. Ovarian tumor cells express a transmembrane serine protease: a potential candidate for early diagnosis and therapeutic intervention. Tumour Biol 2001;22:104-114.

49. Clinton GM, Hua W. Estrogen action in human ovarian cancer. Crit Rev Oncol Hematol 1997;25:1-9.

50. van Doorn HC, Burger CW, van der Valk P, Bonfrer HM. Oestrogen, progesterone, and androgen receptors in ovarian neoplasia: correlation between immunohistochemical and biochemical receptor analyses. J Clin Pathol 2000;53:201-205.

51. Pujol P, Rey JM, Nirde P, Roger P, Gastaldi M, Laffargue F, Rochefort H, Maudelonde T. Differential expression of estrogen receptoralpha and-beta messenger RNAs as a potential marker of ovarian carcinogenesis. Cancer Res 1998;58:5367-5373.

52. Rochefort H, Platet N, Hayashido Y, Derocq D, Lucas A, Cunat S, Garcia M. Estrogen receptor mediated inhibition of cancer cell invasion and motility: an overview. J Steroid Biochem Mol Biol 1998;65: $163-168$.

53. Langdon SP, Hirst GL, Miller EP, Hawkins RA, Tesdale AL, Smyth JF, Miller WR. The regulation of growth and protein expression by estrogen in vitro: a study of 8 human ovarian carcinoma cell lines. J Steroid Biochem Mol Biol 1994;50:131-135.

54. Hayashido Y, Lucas A, Rougeot C, Godyna S, Argraves WS, Rochefort $\mathrm{H}$. Estradiol and fibulin-1 inhibit motility of human ovarian-and breastcancer cells induced by fibronectin. Int J Cancer 1998;75:654-658.

55. Massot O, Baskevitch PP, Capony F, Garcia M, Rochefort H. Estradiol increases the production of alpha 1-antichymotrypsin in MCF7 and T47D human breast cancer cell lines. Mol Cell Endocrinol 1985; 42:207-214.

56. Sheng S, Carey J, Seftor EA, Dias L, Hendrix MJ, Sager R. Maspin acts at the cell membrane to inhibit invasion and motility of mammary and prostatic cancer cells. Proc Natl Acad Sci USA 1996;93:1166911674.

57. Shyamala V, Dickerman HW. Two types of plasminogen activators secreted by MCP-7 cells. Biochem Biophys Res Commun 1982;105: 1597-1604. 